\title{
Um elogio de paixão em A pedra iluminada, de Walmir Ayala*
}

\author{
Luís Alberto dos Santos Paz Filho** \\ Pontifícia Universidade Católica do Rio Grande do Sul \\ Porto Alegre, Brasil \\ Recebido em: 26/03/2019 \\ Aceito em: 21/07/2019
}

Resumo: O presente trabalho propõe uma leitura da produção poética de Walmir Ayala, na obra A pedra iluminada, com o objetivo de analisar os signos de paixão e suas formas de expressão conduzidas pelos sujeitos poéticos dos textos. A partir da perspectiva de Hugo Friedrich, em A estrutura da lírica moderna, no tocante à obscuridade das revelações poéticas típicas do indivíduo moderno, bem como de provocações sobre a construção do eulírico, serão analisados alguns poemas em cujas possibilidades de amor mostrem-se como tarefas distintas, de acordo com as noções singulares de cada "eu" textual.

Palavras-chave: Walmir Ayala. Sujeito poético. Amor. Paixão.

Abstract: The present work is a reading of the poetic production of Walmir Ayala, in the work A pedra iluminada, with the objective of analyzing the signs of passion and its forms of expression led by the poetics of the texts. From the perspective of Hugo Friedrich, in A estrutura da lírica moderna, in regard to the obscurity of revelations, the poetics typical of modern man, as well as the provocation on the construction of the lyrical self, as some similarities of functions of communication with the different tasks, according to the unique notions of each textual "I".

Keywords: Walmir Ayala. Poetic subject. Love. Passion.

Resumen: El presente trabajo propone una lectura de la producción poética de Walmir Ayala, en la obra A pedra iluminada, con el objetivo de analizar los signos de pasión y sus formas de expresión conducidas por los sujetos poéticos de los textos. A partir de la perspectiva de Hugo Friedrich, en A estrutura da lírica moderna, en lo tocante a la oscuridad de las revelaciones poéticas típicas del individuo moderno, así como de provocaciones sobre la construcción del yo-lírico, se analizar algunos poemas en cuyas posibilidades de amor, se trata de tareas distintas, de acuerdo con las nociones singulares de cada "yo" textual. Palabras-chave: Walmir Ayala. Sujeto poético. Amor. Pasión. 


\section{Introdução}

Não é raro olhar para obras literárias e nelas encontrar temas como a morte, a violência e a injustiça. Inúmeras narrativas consolidadas no cânone literário nacional e internacional têm como enredo principal relações de adultério, traição, vingança e assassinato. Isso, infelizmente, não é chocante porque, afinal de contas, estamos em contato com esse tipo de narrativa real diariamente, seja ao nos depararmos com os noticiários televisivos, com as últimas manchetes radiofônicas ou simplesmente ciberrelatos tão aparentemente exagerados, mas verídicos, que colocariam em dúvida a "novidade" artística para a escrita de qualquer literatura de distopia.

Ao se pensar no gênero da poesia lírica, no entanto, é comum que um leitor desavisado (ou mesmo um bem instruído e intencionado) relacione facilmente a essa produção, o amor romântico como principal foco. E não estaria ele absolutamente equivocado. Pelo menos desde a Grécia Antiga, o poeta era revestido de um status profético: era ele o responsável por produzir cantos que elogiariam os deuses e trariam boa fortuna ao povo. Ao longo da história da humanidade, o poeta assumiu diferentes facetas nas diversas sociedades, mas seu caráter de mensageiro divino foi mantido praticamente intocável. No Romantismo brasileiro, por exemplo, o poeta foi um dos responsáveis por estabelecer e divulgar o espírito nacional, bem como as riquezas da nação. Mas se o poeta possui uma aura mágica ou alguma vocação superior não se pode comprovar. Talvez seja só a partir do Modernismo que a poesia perde sua condição sacralizada na história, afinal a linguagem poética passa a objetivar justamente uma espécie de intelectualidade dos sentidos, debruçando suas reflexões sobre a própria língua e os processos comunicativos. Nas palavras de Hugo Friedrich, em Estrutura da lírica moderna (1978), "esta junção de incompreensibilidade e de fascinação pode ser chamada de dissonância, pois gera uma tensão que tende mais à inquietude que à serenidade. A tensão dissonante é um objetivo das artes modernas em geral”. (FRIEDRICH, 1978, p. 15) 
Segundo Octávio Paz, em $O$ arco e a lira (1982, p.15), a poesia "nega a história: em seu seio resolvem-se todos os conflitos objetivos e o homem adquire a consciência de ser algo mais que passagem”. Poesia é, em última instância, uma produção humana e também uma forma de se projetar através do tempo: arte capaz de criar mundos e possibilidades de vida e pensamento, a expressão poética desvela indivíduos através de suas paixões. Segundo Waldir Beividas, em Pulsão, afeto e paixão: psicanálise e semiótica (2006):

o conceito de paixão logo mergulhou num aglomerado terminológico confuso, no qual teve de disputar espaço com afeto, tendência, sentimento, emoção, inclinação, temperamento, sensibilidade, humor, etc. A situação semântica confusa, originada disso, aliada ao fato de que em psicanálise o conceito de paixão ainda recebe uma atenção muito aquém do que pode representar frente à pulsão, tudo isso nos obriga a procurar uma estratégia de entrada na arena da paixão. (BEIVIDAS, 2006, p. 395)

Por outro caminho, nem tão distante, na obra $A$ ética da paixão: uma teoria psicanalítica do afeto (2001), Marcus André Vieira apresenta a perspectiva de que:

há apenas paixão da alma, mas toda paixão é causada pelo corpo. É importante sublinhar o caráter decisivo da afirmação: ainda que tenhamos imaginações instituídas pela alma engendrando paixões, é como representantes do corpo (arts. 44-46), e não da alma, que elas exercem seu papel (art. 34) (VIEIRA, 2001, p. 35)

Tal asserção lacaniana lembra Michel Foucault, em $A$ hermenêutica do sujeito (2006), ao dizer que para a civilização grega antiga, a noção de páthos dizia respeito tanto à paixão da alma quanto a doenças do corpo. Dessa forma, poderia a paixão presente na poesia ser a porta pela qual passam também os males? De acordo com o dicionário etimológico, a palavra paixão tem origem latina na expressão "passionis", que significa também sofrimento. Ao se repensar na Grécia Antiga e em sua mitologia, pode-se associar a história de Eros e Psiquê como uma representação da utopia da paixão, quando beleza e alma formam a conjunção ideal de uma paixão. Seja qual a origem se tome como norte, a paixão parece sempre desmembrada em pelo menos dois componentes: seja corpo e alma, seja alma e 
amor, beleza, mistério, ódio, vingança. Poderia uma obra poética sugerir a paixão como forma de vida?

Em A lógica da criação literária, Kate Hamburger (1986) diz que o diferencial de um texto de natureza lírica (lírica enquanto adjetivo para poesia) é a atitude tomada pelo sujeito-de-enunciação da obra. Poetas como Vinícius de Moraes e Carlos Drummond de Andrade são, até hoje, de certa forma, lembrados por um público mais genérico como escritores da paixão e do amor, como se seus versos representassem um chamado último desse sentimento. Visto por esse ângulo, seria a atitude, mais do que a forma, uma tomada consciente de produção de arte e, por conseguinte, de paixão?

Além de autor de diversas obras literárias, dentre elas romances, contos e crônicas, Walmir Ayala, gaúcho de Porto Alegre, possui uma grande produção de poesia lírica. São mais de dez títulos, sendo o primeiro deles Face dispersa, lançado em 1955, período que assinala sua ida em definitivo para o Rio de Janeiro. Além das produções citadas, Ayala também se dedica ao teatro e à literatura infantil. Sobre esta, por sua vez, ele recebe grande notoriedade, tratando de temas e lendas nacionais, chegando a publicar uma coluna regular nos anos 60 através do Jornal do Brasil. Ele colaborou ainda com diversos jornais como Folha de S. Paulo, Correio da Manhã, Jornal do Commercio, Última Hora, O Dia, e diversas revistas nacionais e internacionais. Em missão cultural do Ministério das Relações Exteriores do Brasil, viajou pela Itália, Chile e Paraguai. Tirante sua vasta produção no campo da Literatura, Walmir Ayala também foi um grande crítico das artes plásticas, tendo escrito, inclusive um Dicionário de pintores brasileiros (1986). Cabe ainda ressaltar que Ayala traduziu diversos autores do espanhol, como Cervantes, Garcia Lorca, José Hernandez e Jorge Luis Borges e produziu obras diarísticas, nas quais relata, além de confidências íntimas, reflexões sobre o estado da arte e do Brasil.

Na poesia de Walmir Ayala, o amor aparece sob diversas manifestações. Para os devidos fins deste trabalho, serão apresentadas três perspectivas: na primeira, o amor é um sentimento manifestado pelo eu-lírico como forma de resposta a um medo de perda e de consequente solidão. A noção de amor para este tipo de sujeito poético está atrelada à necessidade de compartilhamento das experiências, como uma relação entre dois seres. Há uma entrega desmedida, típica da paixão, que 
arrebata. Dessa forma, a noção de amor parece existir como ícone oposto à ideia de razão, como se o amor fosse um sentimento avassalador irrefreável. No poema Declaração, o eu-lírico se dispõe a amar as imperfeições e as inexatidões do “outro”, como uma maneira de declarar abertamente a entrega total ao sentimento. Ele diz amar a tristeza e o temor do outro, assim compreendendo de alguma maneira que essa relação amorosa necessita da fragilidade. A fraqueza dos sujeitos presente neste poema revela ainda um grau elevado de humanidade, uma vez que errar e sofrer faz parte do êxtase alcançável pelo amor. Observemos a seguir:

\section{Declaração}

Eu amo a tua inocência, Amor, Tua tristeza, esta flor Mesmo da tua inclemência.

Amo teu temor sem causa, amor.

Tua carne cautelosa, Tua alma deplorada Que me abrasa.

Tira tudo o que em ti amo, Amor

Esta tristeza, este mito, Este claustro, este abandono, Mas não me tires a vida Deste sonho.

$$
\text { (AYALA, 1976, p. 21) }
$$

No poema transcrito, a colocação pronominal de primeira pessoa do singular está explícita, assim como o correspondente em segunda pessoa também do singular, que não responde, isto é, não está presente parece existir no plano geral da receptividade. A comunicação estabelecida lembra a de uma carta, na qual um “eu” escreve para um outrem que receberá as informações ali depositadas. Além de a fala ser unilateral por parte do sujeito poético, outro fator que enriquece a possibilidade de se tratar de uma espécie de carta é o título do poema: “declaração", 
o que remonta aos gestos românticos de um dado período, no qual um indivíduo, geralmente, anonimamente explicitava sua paixão por outro.

Na primeira estrofe do poema, que consiste em quatro versos curtos, é interessante notar o segundo: uma única palavra que simboliza, ao mesmo tempo, um vocativo indicativo da segunda pessoa pronominal com a qual o eu-lírico dialoga, e, também, o sentimento que tematiza seu discurso. Ainda nesta estrofe, outro elemento que se faz destacar é o comparativo das palavras inocência e tristeza a uma flor. Assume-se, de modo generalizado, que a flor simbolize elementos revestidos de uma certa positividade, como a paixão e a beleza. Neste caso, no entanto, o sujeito poético associa a "flor da inclemência" a fraquezas deste outro com quem ele estabelece comunicação. A inocência e a tristeza do outro tornam-se matérias amáveis por este eu, o que revela, em última instância, sua dedicação em gostar de cada detalhe que forma o caráter de seu amante - mesmo o mais obscuro de seus sentimentos.

Na segunda estrofe, a noção de amor retoma uma visão mítica de união entre corpo e alma, sinalizando para uma possibilidade de completude, da qual o sujeito fosse capaz de compreender a essência do ser humano. A “carne cautelosa” e a "alma deplorada" são elementos ressignificados que evocam a devoção deste amor, sem limites. Além disso, neste primeiro verso "amo teu temor sem causa, amor", mostra-se que não há barreiras que não possam superadas, mesmo o medo. Inclusive, temor e amor parecem ser opositivos, visto que condensam em si sensações que despertam memórias sentimentais distintas. Segundo Octavio Paz, em $O$ arco e a lira (1982),

o poema não só proclama a coexistência dinâmica e necessária de seus contrários como sua identidade final. E essa reconciliação, que não implica redução nem transmutação da singularidade de cada termo, é um muro que até agora o pensamento ocidental se recusou a saltar ou a perfurar. (PAZ, 1982, p. 123)

O poema se desenvolve de forma a apresentar, a cada verso e estrofe, elementos que integrem um contexto maior e mais profundo do sentimento do eulírico pelo outro. Conforme dito anteriormente, é quase como se a falta de força presente no indivíduo fosse um motivo desconcertante para que o sentimento 
prosseguisse e evoluísse numa forma de dependência. Afinal, na terceira e última estrofe do texto, o sujeito poético chega a revelar "Tira tudo o que em ti amo / [...] / Mas não me tires a vida / Deste sonho". Parece que o desejo da possibilidade desta relação, no plano do sentimento, é mais importante do que a concretização em si. O sonho ou a possibilidade desta vida imaginada têm maior peso na balança da vida do eu-lírico. Estas são marcas de uma espécie de corrupção do romantismo, como se fosse preciso amar tudo o que há de negativo (noção subjetiva que depende de um exercício de alteridade) no outro para que o amor seja alcançado.

A segunda perspectiva aqui elencada é a noção de amor que diz respeito a um senso de coletividade. Neste espectro de enunciações do sujeito poético, a noção de amor responsabiliza uma noção de todo para a concretização de um sentimento capaz de elevar uma ideia de universal. $O$ amor aqui não é unicamente autocentrado. Também não há necessidade de uma relação dual/dialógica entre dois seres. No poema Viola, assim como os verbos são apresentados na terceira pessoa do plural, o amor também é algo plural: "Cantavam canção de amor”, diz o eu-lírico. E cantando, é como se todos também pudessem amar. Ele diz ainda "E a canção seguia / Tão igual a tudo meu". No entanto, este "eu" se oculta novamente no manto de um "nós” que emerge da própria canção. E os silêncios construídos ao longo do discurso são reflexos do apagamento dessa voz da sociedade que, ao se calar, cala o amor em si e nos outros. Conforme segue:

\section{Viola}

Cantavam canção de amor

Ao meu lado, havia sombra, Um laivo de prata ardente

Uma languidez de alfombra.

Cantavam canção de amor.

Quem cantava ia dizendo coisas minhas, tão secretas, Que eu fechei as mãos e os olhos

Temendo as portas abertas.

Fechei, e a canção seguia

Tão igual a tudo meu

Que eu temi ouvir teu nome 
Na canção que se seguia.

Mas nada, ninguém sabia.

Apenas o amor que é triste

Perto, longe, noite e dia,

Sempre algo que se perdeu

De encontro que não existe,

E é pura desalegria.

Mas tão milagroso e certo

Que a canção se repetia.

(AYALA, 1976, p. 51)

No poema Viola, os primeiros versos já se mostram ricos: a interpretação das reflexões transmitidas pelo sujeito poético é realizada por uma terceira pessoa do plural ("cantavam"), o que permite com que ele mantenha distância dos fatos e sentimentos descritos, ao passo que se camufla em uma primeira pessoa do singular oculta no discurso. Eles cantavam canção de amor, diz o eu-lírico no primeiro verso, mas no segundo aparece "Ao meu lado, havia sombra”. Surge um efeito de comparação e reflexão eles x eu. Quais seriam os efeitos e em quê implicariam as ações 'deles' no 'eu'? A segunda estrofe é composta por um único verso: "Cantavam canção de amor", como o refrão de uma música. É quase como se o poema acerca dessa canção de amor já fosse a própria canção de amor. Um metapoema que se descreve ao descrever a ação de um "eles” em detrimento de um “eu.

Ao longo da terceira estrofe, o sujeito poético revela a relação com estes que cantavam. Ao passo que a música crescia, seus segredos eram descobertos, como se o amor cantado fosse, na verdade, o que ele escondia. A relação do sujeito da enunciação com o amor revela uma noção diferente da experienciada no poema anteriormente analisado. Aqui, o amor parece depender de um senso social de aprovação, como "eles" se tornassem "nós” para, assim, possibilitar o "eu”. A quarta estrofe trata justamente de se fechar para o mundo e para a possibilidade da concretização do amor, afinal a clandestinidade e anonimato do amor parece serem as defesas ideais para a manutenção da relação desejada pelo sujeito poético. Assim como o título do poema sugere, a viola é como um instrumento-primo do 
violão, que exige maior sutileza em suas cordas, também o amor não está na grandeza, mas em sua plenitude, a partir de sua admissão.

Ao chegar às duas últimas estrofes do poema, a ideia discutida no parágrafo anterior parece se comprovar. Na primeira estrofe há "Mas nada, ninguém sabia", e, assim, a tristeza toma conta, porque o que antes era segredo torna-se público, enquanto eles cantam. Porém, o que parecia perdido é a reavivado: o amor que era triste, na verdade, é "milagroso e certo" e fazia a canção continuar e retornar. E, em última análise, enquanto há canção, há amor. É importante que nada há de derradeiro ou definitivo na leitura dos poemas aqui apresentados. Cabe a cada leitor decifrar as possibilidades de mundo evocadas no discurso dos sujeitos líricos. Em paralelo, pode-se pensar na assertiva de Hugo Friedrich, ao dizer que

ao princípio, não se poderá aconselhar outra coisa a quem tem boa vontade do que procurar acostumar seus olhos à obscuridade que envolve a lírica moderna. Por toda a parte, observamos nela a tendência de manter-se afastada o tanto quanto possível da mediação de conteúdos inequívocos. A poesia quer ser, ao contrário, uma criação auto-suficiente, pluriforme na significação, consistindo em um entrelaçamento de tensões de forças absolutas, as quais agem sugestivamente em estratos pré-racionais, mas também deslocam em vibrações as zonas de mistério dos conceitos. (FRIEDRICH, 1978, p. 16)

Embora Friedrich esteja tratando da poesia moderna, sua dica cabe à leitura de grande parte dos textos poéticos, uma vez que existe a tendência ululante que envolve a obra e a torna embaçada e enigmática. Mas esta é uma das grandes magias: a sugestão, a hipótese. Ao retornar à leitura dos poemas de Ayala, nos deparamos com aquilo que aqui será chamada de terceira abordagem proposta, na qual o amor vincula-se à noção de desejo. Este desejo diz respeito, de forma geral, a uma relação corporal: o toque, o cheiro, o sabor. No poema "Corpo", a massa humana é representada como usina quebrada, um receptáculo condenado. Há uma desesperança que ronda a ideia de um sujeito-máquina cujas funções estão avariadas. Ainda assim, diz o sujeito lírico, o corpo é o "santo fogo da vida", afinal é nele e por ele que passa a possibilidade de ser, existir e inventar. Neste poema, o corpo é associado à natureza, ao compará-lo a uma árvore que nutre a vida, e a um animal que carrega a bandeira da resistência. A idealização da primeira ideia 
apresentada é abandonada e o amor vive no inconsequente plano material. Amar, sob esta ótica, é desejar. Eis o poema exemplo:

\section{Corpo}

Usina de amor tombada, Engrenagem de mel que ressona, Tecido resguardado, flor de nervos Que aberta fulge.

Corpo - santo fogo da vida.

Deposto és rei, Nu és ouro puro.

Corpo - corola onde a minha insônia bebe.

Raiz da minha loucura

Que rasteja

Para depois ser luz e êxtase.

Árvore, pelagem, sal, areia, Rastro, solidão, gemido,

Tremor e febre: corpo.

Animal que ampara o mundo

Bandeira e balança

Caule e ramo verde - segurança da arca,

Anti-rosa, verme ardente.

Eternidade que se nega, corpo Eu beijo a tua morte, residente.

(AYALA, 1976, p. 68)

Se o corpo é uma máquina fracassada e esquecida como uma usina tombada, o que pode, senão o amor, ser o lubrificante ideal para a socialização necessária e a apreensão de um sentimento que transcenda suas próprias engrenagens? $\mathrm{O}$ homem-máquina evocado no poema transcrito lembra, de imediato, a ideia da tomada da cientificidade em detrimento do homem, um dos valores que contamina os idéias de Modernismo. Embora a linguagem esteja sempre aquém do que se deseja transmitir, o sujeito poético parece denunciar a condição descartável do indivíduo e pedir atenção para os sentimentos. 
Em contraposição à ideia da primeira estrofe, ao inicia a segunda, o eu-lírico santifica e coloca em posição Real o corpo como o epicentro da vida: ao passo que é filtro e acolhimento, também é raiz e luz. Através da evocação sinestésica dos elementos naturais, como uma simbiose genética entre vontade e toque, o poema se desenvolve de forma a dar espaço para a noção de amor que não condena o corpo como pecado, mas sim glória. Não há um rebaixamento do status de mundano relacionado à estrutura humana, mas parece haver quase um pedido de socorro, uma bandeira que balança, conforme suscitado na quarta estrofe. $\mathrm{O}$ indivíduo funde-se à própria natureza, porque é o natural que ascende a condição humana a algo mais do que passagem e invólucro que enferruja e é jogado fora: "Caule e ramo verde - segurança da arca, / Anti-rosa, verme ardente”. Um jogo de sentidos estabelecidos por uma herança do Simbolismo francês, com elementos provocativos que incendeiam a imaginação através de insinuações carnais e etéreas.

O discurso de amor surge como uma forma de manifesto: nos tempos modernos ainda é possível amar? O que é o corpo? A quem pertence? Quais são suas funções sociais? Como se expressar através do movimento, do sexo, do toque, da recusa? Qual é a sua durabilidade? E a resposta: o eterno. Vivemos para fora ou enclausurados nele? Que tipo de democracia trata do corpo-raiz? E o corpo-ouro? E o corpo-solidão? Eis os signos evocados pelo eu-lírico para explicar: "Rastro, solidão, gemido, / tremor e febre: corpo”. Se há uma forma de amar, o corpo precisa ser passagem, rito de iniciação, ciclo final. Como pode ser errado habitar seu próprio desejo? Talvez esta seja uma tendência a mais criar questões do que tentar respondê-las. Segundo Jacques Lacan, em A ética da psicanálise (2008):

o estabelecimento do ehtos é feito como que diferenciando o ser vivo do ser inanimado, inerte. Como salienta Aristóteles, por mais vezes que vocês lancem uma pedra no ar ela não se habituará à sua trajetória, enquanto que o homem, este se habitua - esse é o ethos. E esse ethos, trata-se de obtê-lo conforme ao ethos, ou seja, a uma ordem que é preciso reunir, na perspectiva lógica que é a de Aristóteles, num Bem Supremo, ponto de inserção, de vínculo, de convergência, em que uma ordem particular se unifica num conhecimento mais universal, em que a ética desemboca numa política e, mais além, numa imitação da ordem cósmica. (LACAN, 2008, p. 33) 
De acordo com o citado anteriormente, este trabalho intentou criar provocações. Como se configuram os discursos de paixão e amor na produção lírica moderna? Como Ayala constrói discursos poéticos? De que é feita a linguagem amorosa na literatura? Pode o indivíduo criar um hábito para amar e ser amado? Outros poemas poderiam exemplificar cada uma das perspectivas assumidas no decorrer da elaboração deste trabalho. De acordo com Kate Hamburger, a atitude lírica é o que dita o discurso textual do poema. Mas como identificar um discurso poético sem destrinchá-lo em níveis semânticos, sintáticos, paradigmáticos e tantos outros? Se, conforme Lacan, toda paixão de corpo passa necessariamente pela alma, poderia o texto poético de Walmir Ayala ser antes de uma composição melódica uma estrutura amorosamente discursiva? Fala-se de amor e sobre amor como se fosse sempre uma idealização particular e datada. Atribui-se um valor ingênuo à questão. Se durante alguns momentos da história a poesia esteve diretamente vinculada a alguma forma de exibição de paixões, a literatura parece, por vezes, desprovida de sensibilidade. Ou talvez sejam os sujeitos que a recebem que não estão interessados em nutrir alguma compaixão. Se toda forma de amor é bem-vinda - e acredita-se que sim - então há alguma esperança em meio a tempos nebulosos de resgatar alguma coletividade compassiva e preocupada em dar voz a um sentimento que diz respeito a todas e a todos.

\section{Referências}

AYALA, Walmir. A pedra iluminada. Rio de Janeiro: Pallas S.A, 1976 FOUCAULT, Michel. A hermenêutica do sujeito. São Paulo: Martins Fontes, 2006. FRIEDRICH, Hugo. Estrutura da lírica moderna: da metade do século XIX a meados do século XX. Trad. Marise M. Curioni. São Paulo: Duas cidades, 1978. HAMBURGER, Käte. A lógica da criação literária. Editora Perspectiva, 1986. LACAN, Jacques. (1959-1960). Livro 7: A ética da psicanálise. Rio de Janeiro: Jorge Zahar, 1991. 
PAZ, Octavio. O arco e a lira. Trad. Olga Savary. Rio de Janeiro: Editora Nova Fronteira, 1956.

SEFFRIN, André. Walmir Ayala. Disponível em:

<http://www.jornaldepoesia.jor.br/wayala.html> Acesso em 16.02.2019

VIEIRA, Marcus André. A ética da paixão: uma teoria psicanalítica do afeto. Rio de Janeiro: Jorge Zahar, 2001.

WALMIR AYALA. Autores gaúchos. № 22. Porto Alegre: Instituto Estadual do Livro, 1989.

WALMIR AYALA. Disponível em: <https://globaleditora.com.br/autores/biografia/?id=1737> Acesso em: 20.03.2019

${ }^{*}$ O presente trabalho foi realizado com apoio da Coordenação de Aperfeiçoamento de Pessoal de Nível Superior - Brasil (CAPES).

** Doutorando em Teoria da Literatura no Programa de Pós-Graduação em Letras da Pontifícia Universidade Católica do Rio Grande do Sul (PUC-RS). 